\title{
Observations made on three patients suffering from ulcers of the lower limbs treated with Blue Light
}

This article was published in the following Dove Press journal:

Chronic Wound Care Management and Research

\author{
Giovanni Mosti' \\ Stefano Gasperini² \\ 'Barbantini Clinic, Lucca, Italy; \\ ${ }^{2}$ Medical Advisor, Pisa, Italy
}

Correspondence: Stefano Gasperini Via Cavour 4 - 56I27 Pisa, Italy Tel +39334794 2429 Email gasperini.medicaladvisor@gmail. com

\begin{abstract}
Chronic skin lesions are an important medical health problem. Chronic skin lesions are associated with high costs for the National Health Service and reduced quality of life for the patient. The availability of means to reduce the healing time of skin ulcers is a medical and public health priority. Within this context, for patients suffering from skin ulcers, great attention has been given to the use of particular frequencies of the light spectrum that have shown beneficial effects on both ulcer cleansing and healing stimulation. This article reports the observations made on three patients suffering from ulcers of the lower limbs who were treated with Photobiomodulation therapy using Blue Light in addition to the standard treatment at a private clinic. The results were encouraging and have prompted us to participate in a protocol of a multicenter randomized study on a significant number of patients.

Keywords: photobiomodulation, blue light emitting diodes, wound healing, chronic leg skin lesion
\end{abstract}

\section{Introduction}

The treatment of chronic skin wounds (or skin ulcers) is an important concern from both a medical and a financial point of view as it represents one of the most expensive healthcare services in the world: around $3 \%$ of the health budget is spent on treating this kind of injury, which is increasingly widespread and has a high social impact. A recent study (84 patients with lower limb venous ulcers), in which the ulcers were treated in a reasonable period of time (approximately120 days), showed an estimated cost of $\$ 15,000$, with the treatment costs rising to about $\$ 34,000$ when the ulcer had a delayed recovery time. ${ }^{1}$

Every year, approximately 6.5 million cases of chronic cutaneous ulcers from venous insufficiency, pressure, and diabetes mellitus are registered in the United States. ${ }^{2}$ According to the latest guidelines of the European Dermatology Forum, lower limb ulcers affect between $1.5 \%$ and $3 \%$ of the general population and the percentages reach $4 \%-5 \%$ in patients aged $\geq 80$ years. ${ }^{3}$ A study carried out in the United Kingdom (THIN report, The Health Improvement Network, 2012-2013) ${ }^{4}$ showed that the treatment costs of cutaneous ulcers is approximately 4-5 billion pounds per year. This is the equivalent of roughly $4 \%$ of total UK National Health costs, a percentage destined to rise steadily with its aging population. ${ }^{4}$

In Italy, there are no recent studies that are similarly well structured, as the collection of data is not yet precise and uniform and there is no communication and integration between the existing national organizations. It is estimated that in Italy patients suffering from ulcers in the lower limbs are approximately 2 million, of which $70 \%$ with venous type ulcers, and that the expense for the treatment of these diseases sustained 
by the National Health Service is around 1 billion euros per year. ${ }^{5}$ In Italy, the national prevalence of patients with lower limb injuries corresponds to $16 \%$ of the total number of patients assisted with Integrated Home Care Services ADI (A.I.S.Le.C. - Associazione Italiana Infermieristica per lo studio delle Lesioni Cutanee, 2013). It is also believed that about $30 \%$ of patients in Italy who have suffered from diabetes for at least 10 years have a form of diabetic neuropathy with $15 \%$ of these being hospitalized due to distal ulcers. ${ }^{6}$

Thanks to the work accomplished in recent years by the relevant Scientific Societies (AIUC - Associazione Italiana Ulcere Cutanee, AISLeC - Associazione Italiana Infermieristica per lo studio delle Lesioni Cutanee, CORTE - Conferenza Italiana per lo studio e la ricerca sulle ulcere, piaghe, ferite e la riparazione tissutale), the concern regarding the prevalence of the disease with its economic and social impact has emerged, and its gravity is generally accepted.

Currently, the therapeutic challenge is focused on shortening the time by both setting correct diagnostic-therapeutic procedures and recommending the appropriate use of effective and technological devices.

The therapeutic application of light at low doses and intensities, termed Photobiomodulation Therapy (PBMT), is currently performed for the treatment of various dermatologic pathologies.

Within this context, for patients suffering from skin ulcers, great attention has been given to the use of particular frequencies of the light spectrum which have shown beneficial effects on both ulcer cleansing and healing stimulation. Abundant literature has been produced in recent years demonstrating that the PBMT provides benefits in tissue repair ${ }^{7-9}$ with a series of effects such as increased capillary and vascular circulation; promoting vasodilation and angiogenesis through the metabolism of Nitric Oxide (NO): ${ }^{10}$ stimulation of ATP synthesis, an essential energy source for the metabolism of all cellular processes, including tissue repair; ${ }^{11}$ reduction of scar tissue formation and keloids; ${ }^{11}$ stimulation of fibroblast activity with increased collagen deposition and connective tissue repair. ${ }^{11}$

In particular, the specific range of light frequencies between 400 and $450 \mathrm{~nm}$ (Blue Light) has proved to be effective in many applications such as the reduction of the bacterial load: ${ }^{12-14}$ the treatment of skin diseases such as acne, ${ }^{12,15,16}$ psoriasis, ${ }^{17,18}$ and eczema; ${ }^{19}$ and for the treatment of skin lesions. ${ }^{20-22}$ Further evidence shows that PBMT with Blue Light has an antiinflammatory potential as it inhibits the pathways involved in the inflammatory response ${ }^{23}$ and is able to reduce the release of proinflammatory cytokines. ${ }^{24}$
This article reports the observations made on three patients suffering from ulcers of the lower limbs who were treated with PBMT using Blue light emitting diodes (LEDs) irradiation in specific wavelengths $(410-430 \mathrm{~nm})$, in addition to the standard treatment at a private clinic.

\section{Materials and methods}

The observations were made on three voluntary patients suffering from chronic lesions of different etiology on the lower limbs treated with a Blue Light medical device to aid the skin lesion healing.

The LED irradiation system, a prototype device provided by EMOLED srl (Florence, Italy), is portable and equipped with rechargeable batteries. The Blue Light device illuminates a circular $5 \mathrm{~cm}$ diameter area for 1 minute, providing an LED radiation at $120 \mathrm{~mW} / \mathrm{cm}^{2}$ power density at a distance of $4 \mathrm{~cm}$ from the wound bed, which corresponds to an energy density dose of $7.2 \mathrm{~J} / \mathrm{cm}^{2}$.

The device does not come into contact with the lesion, and its action mechanism is based on the stimulation of natural chromophores through the emission of Blue Light (400-430 nm, $\lambda_{\text {MAX }}: 415 \mathrm{~nm}$ ).

Following the standard cleansing procedure of the lesion, at each visit, the patient was exposed to applications of Blue Light which were carried out for 1 minute on each circular 5 $\mathrm{cm}$ diameter area until the entire lesioned area was covered. Following the Blue Light treatment, the appropriate medication and dressing for the type of lesion were applied according to the required standard. The Blue Light treatment on these patients was well accepted and tolerated, and there were no reports of side effects or other adverse events.

\section{Results}

\section{Patient I}

The first patient treated with this technology was a 90-year-old man with chronic venous insufficiency, diabetic who regularly took insulin, and had a problem with recurring venous ulcers over a 50-year period. The patient had been in treatment at the clinic on and off for years and in the period preceding the Blue LEDs treatment, various therapies were attempted without success. The age of the treated ulcer was 36 months. Five treatments with the Blue Light device were performed in 12 weeks.

In this period, an improvement of the wound bed, a reduction of the lesion depth, and a revitalization of the perilesional skin were observed (Figure 1). These results, we believe, were sufficient to reactivate the lesion which appeared silent for over 3 years despite various therapeutic attempts undertaken. 


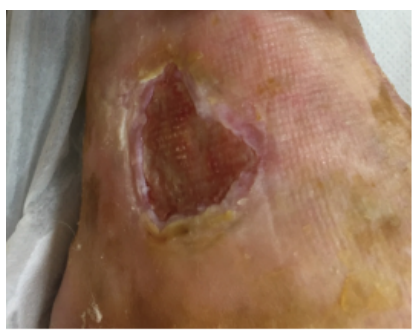

Beginning of observation

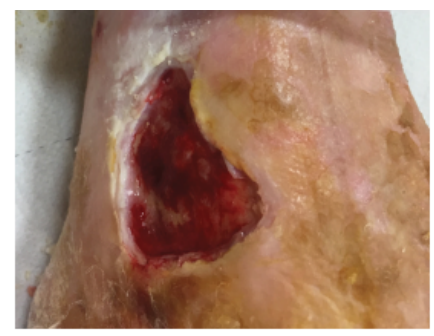

Week 8

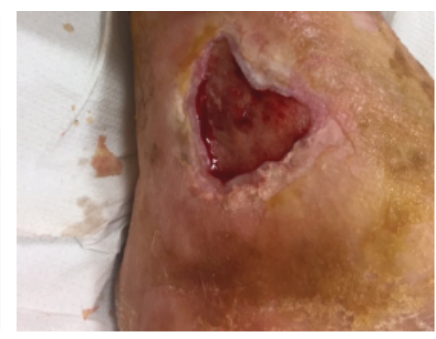

End of observation

Figure I Patient I: Recurrent leg ulcer.

It had always been medicated with advanced dressing and proper elastic compression. The effect of blue light has allowed revitalization of the wound bed and, thus, a probable recovery.

\section{Patient 2}

The second patient was a 78-year-old woman with bilateral arteriopathy. This patient had undergone various treatments at the clinic for some time. She had revascularization surgery on her right leg and several skin grafts on both legs. When the patient began PBMT with Blue Light, she had ulcers on both legs (Figure 2).

The right leg had a fairly superficial yet extended lesion. After two Blue Light applications, the lesion closed completely.

The left leg, however, showed lesions which exposed the bone tissue and underwent 11 applications over a 21-week period, always combined with advanced dressing and elastic compression. During this period, the patient had irregular treatments due to seasonal health problems, which consequently slowed the lesion healing process. At the end of this period, however, the lesions were reduced by $>90 \%$ (Figure 3 ). The left limb showed evident repair difficulties due to the poor supply of arterial blood in the periphery, so we believe that the action of Blue Light has been decisive for achieving the result shown.

\section{Patient 3}

The third observation was carried out on a 40 -year-old male and former addict with venous stasis ulcers in both lower limbs which had been present for 7 years. This patient came to our observation with a clinical history of poor results. Repeated skin grafts of both dermal and autologous substitutes were conducted in another clinic, resulting in only a slight reduction of the ulcer's surface area.

The therapeutic protocol for this patient included standard weekly dressings with wound cleansing, use of hydrophobic dressing, and compression therapy. Treatment with the Blue

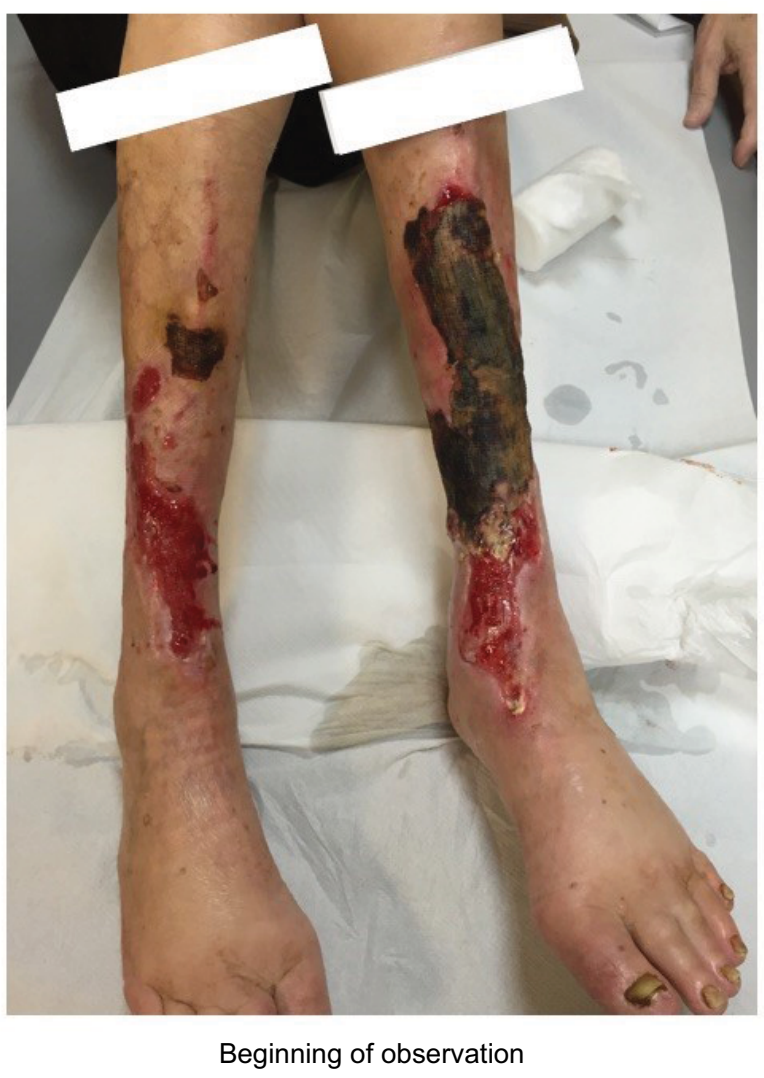

Figure 2 Patient 2: Skin ulcers on the left and right legs.

Light device (performed eight times in 9 weeks) was performed on the upper ulcer of the right leg and on one ulcer of the left leg; only the half upper part of the left leg ulcer was treated.

With regards to the lesion treated on the right leg, healing was achieved after four treatments in 4 weeks. The untreated lesions showed improvement though they did not completely heal (Figure 4).

With regards to the left leg half-treated lesion after eight treatments in 9 weeks, $95 \%$ reepithelialization was achieved 


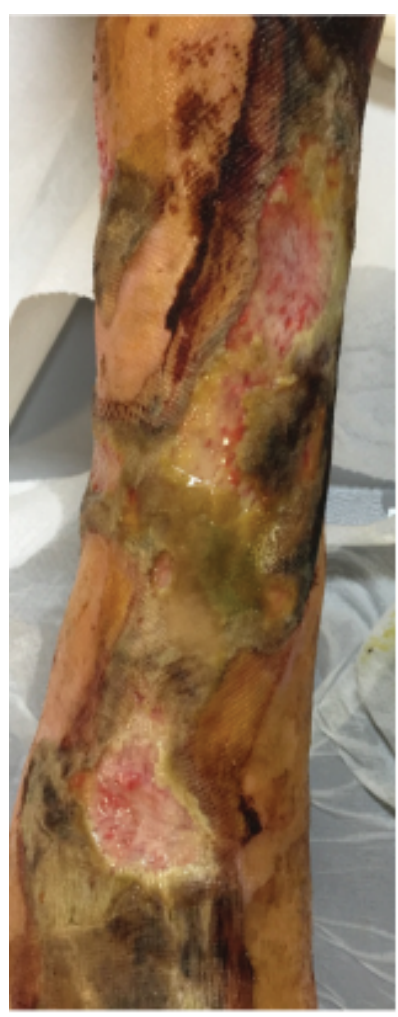

Beginning of observation

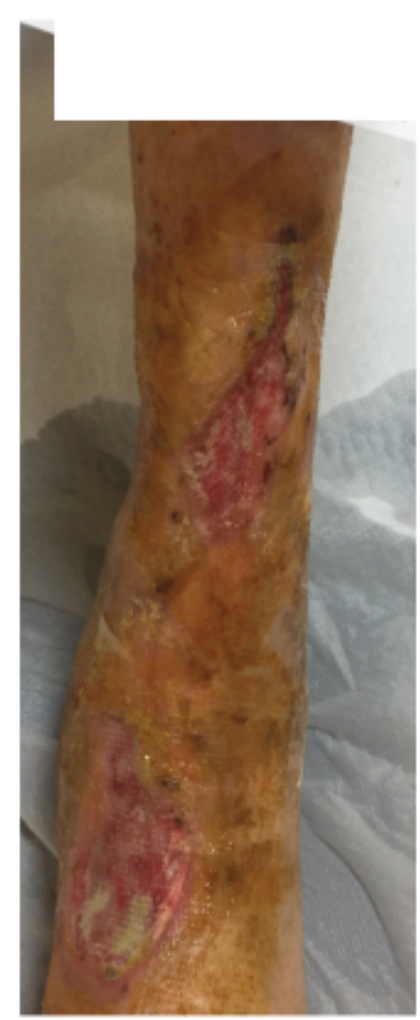

Week 11

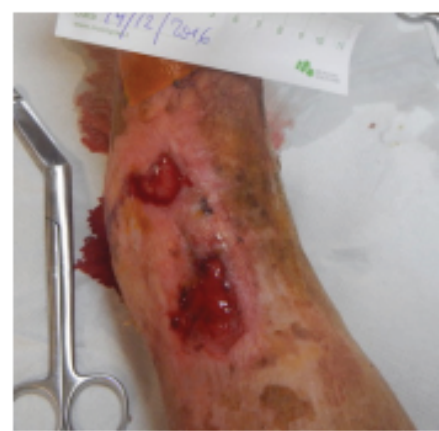

End of observation

Figure 3 Patient 2: Skin ulcer on the left leg.

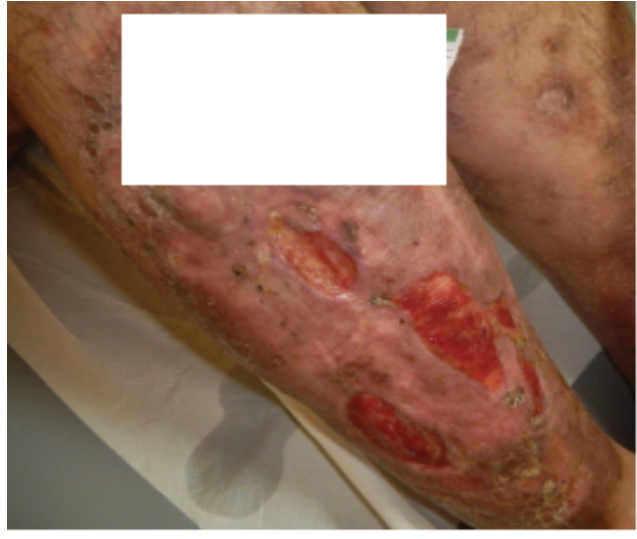

Beginning of observation

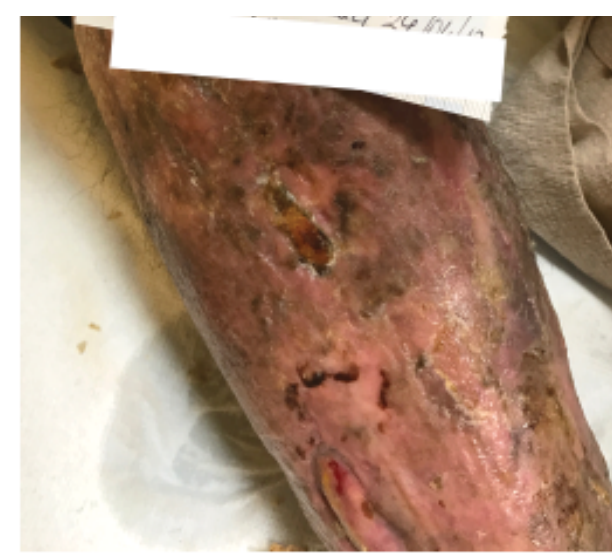

End of observation

Figure 4 Patient 3: skin ulcers on the right leg: only the upper lesion has been treated.

in the treated region and an $80 \%$ reepithelialization in the untreated region (Figure 5).

\section{Conclusion}

During our small experience, we added only the PBMT with irradiation of Blue Light on the ulcer with the standard treatment, with the aim of verifying whether the use of this treatment could be well tolerated, did not produce unpleasant or undesirable reactions for the patient, and finally, if it could in fact facilitate the lesion's healing process. The results were encouraging and have prompted us to participate in a protocol of a multicenter randomized study on a significant 


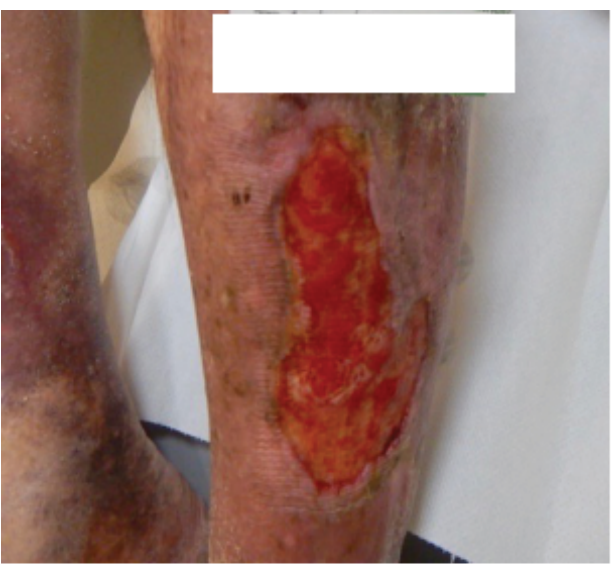

Beginning of observation

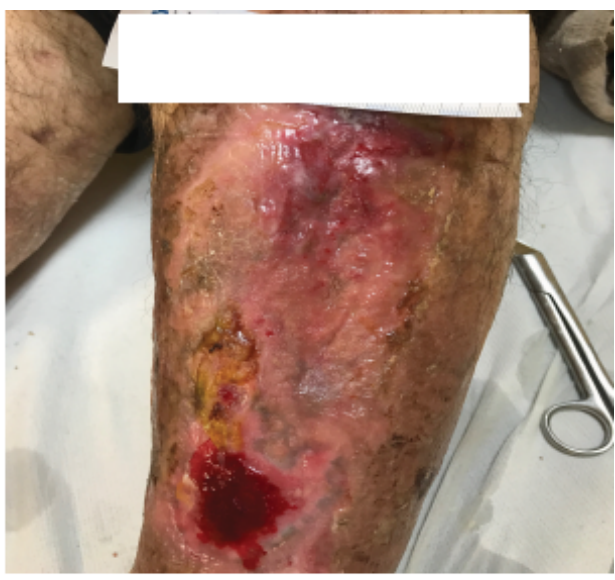

End of observation

Figure 5 Patient 3: skin ulcer on the left leg; upper half treated.

number of patients that we hope will verify the efficacy of the PBMT we observed on a significant case series of patients.

\section{Patient consent to publish}

Written informed consent has been provided by the patients to have the case details and any accompanying images published.

\section{Disclosure}

The two authors report their conflict of interest in the work as consultants and advisory board members of Emoled srl, the company which has provided the Blue Light prototypal device used.

\section{References}

1. Ma H, O’Donnell TF, Rosen NA, Iafrati MD. The real cost of treating venous ulcers in a contemporary vascular practice. J Vasc Surg Venous Lymphat Disord. 2014;2(4):355-361.

2. Markova A, Mostow EN.US skin disease assessment: ulcer and wound care. Dermatol Clin. 2012;30(1):107-111.

3. Neumann HA, Cornu-Thénard A, Jünger M. Evidence-based (S3) guidelines for diagnostics and treatment of venous leg ulcers. $J$ Eur Acad Dermatol Venereol. 2016;30(11):1843-1875.

4. Guest JF, Ayoub N, Mcilwraith T, et al. Health economic burden that different wound types impose on the UK's National Health Service. Int Wound J. 2017;14(2):322-330.

5. Marigo L, Vison A. Lower limb ulcers: integrated outpatient treatment. Acta Vuln. 2007;5:103-104.

6. Gerstein H, Hunt D. Foot ulcers and amputations in diabetes. Clin Evid. 2002;(7):521-528.

7. Lubart R, Landau Z, Jacobi J, Friedmann H. A new approach to ulcer treatment using broadband visible light. Laser Therapy. 2007;16(1):7-10.

8. Caetano KS, Frade MA, Minatel DG, Santana LA, Enwemeka CS. Phototherapy improves healing of chronic venous ulcers. Photomed Laser Surg. 2009;27(1):111-118.

9. Landau Z, Migdal M, Lipovsky A, Lubart R. Visible light-induced healing of diabetic or venous foot ulcers: a placebo-controlled double-blind study. Photomed Laser Surg. 2011;29(6):399-404.
10. Ankri R, Friedman H, Savion N, Kotev-Emeth S, Breitbart H, Lubart R. Visible light induces no formation in sperm and endothelial cells. Lasers Surg Med. 2009;42(4):348-352.

11. Enwemeka CS. Therapeutic light. Rehab Manag. 2004;17(1):20-27.

12. Dai T, Gupta A, Murray CK, Vrahas MS, Tegos GP, Hamblin MR. Blue light for infectious diseases: Propionibacterium acnes, Helicobacter pylori, and beyond? Drug Resist Updat. 2012;15(4):223-236.

13. Halstead FD, Thwaite JE, Burt R, et al. Antibacterial activity of blue light against nosocomial wound pathogens growing planktonically and as mature biofilms. Appl Environ Microbiol. 2016;82(13):4006-4016.

14. Wang Y, Wang Y, Wang Y, et al. Antimicrobial blue light inactivation of pathogenic microbes: state of the art. Drug Resist Updat. 2017;33-35:1-22.

15. Noborio R, Nishida E, Kurokawa M, Morita A. A new targeted blue light phototherapy for the treatment of acne. Photodermatol Photoimmunol Photomed. 2007;23(1):32-34.

16. Glitzner E, Korosec A, Brunner PM, et al. Specific roles for dendritic cell subsets during initiation and progression of psoriasis. EMBO Mol Med. 2014;6(10):1312-1327.

17. Félix Garza ZC, Liebmann J, Born M, Hilbers PA, van Riel NA. A dynamic model for prediction of psoriasis management by blue light irradiation. Front Physiol. 2017;8:28.

18. Keemss K, Pfaff SC, Born M, et al. Prospective, randomized study on the efficacy and safety of local UV-free blue light treatment of eczema. Dermatology. 2016;232(4):496-502.

19. Tremblay JF, Sire DJ, Lowe NJ, Moy RL. Light-emitting diode $415 \mathrm{~nm}$ in the treatment of inflammatory acne: an open-label, multicentric, pilot investigation. J Cosmet Laser Ther. 2006;8(1):31-33.

20. Adamskaya N, Dungel P, Mittermayr R, et al. Light therapy by blue LED improves wound healing in an excision model in rats. Injury. 2011;42(9):917-921.

21. Dungel P, Hartinger J, Chaudary S, et al. Low level light therapy by LED of different wavelength induces angiogenesis and improves ischemic wound healing. Lasers Surg Med. 2014;46(10):773-780.

22. Cicchi R, Rossi F, Alfieri D, et al. Observation of an improved healing process in superficial skin wounds after irradiation with a blue-LED haemostatic device. J Biophotonics. 2016;9(6):645-655.

23. Becker A, Sticht C, Dweep H, et al. Impact of blue LED irradiation on proliferation and gene expression of cultured human keratinocytes. Progress in Biomedical Optics and Imaging - Proceedings of SPIE. 2015; 9309; San Francisco, CA.

24. Fischer MR, Abel M, Lopez Kostka S, et al. Blue light irradiation suppresses dendritic cells activation in vitro. Exp Dermatol. 2013;22(8): 558-560. 


\section{Publish your work in this journal}

Chronic Wound Care Management and Research is an international, peer reviewed, open access, online journal publishing original research, reviews, editorials, and commentaries on the causes and management of chronic wounds and the major issues related to chronic wound management. Topics also include chronic wounds as comorbidities to other conditions, patient adherence to therapy, and the economic burden of chronic wounds. The manuscript management system is completely online and includes a very quick and fair peer review system, which is all easy to use. Visit http://www.dovepress.com/testimonials.php to read real quotes from published authors.

Submit your manuscript here: https://www.dovepress.com/chronic-wound-care-management-and-research-journal 